\title{
Systems and Complexity Thinking in the General Prac- tice Literature: An Integrative, Historical Narrative Review
}

\author{
Joachim P. Sturmberg, MBBS, Dip \\ RACOG, FRACGP, MFM, PbD ${ }^{1}$ \\ Carmel M. Martin, MBBS, MSc, \\ $\mathrm{PbD}$, MRCGP, FRACGP FAFPHM ${ }^{2}$
}

David A. Katerndabl, $M D, M A^{3}$

'Department of General Practice, Newcastle University, Newcastle, New South Wales, Australia

${ }^{2}$ Department of Public Health Primary Care, Trinity College Dublin, Ireland

${ }^{3}$ Department of Family \& Community Medicine, University of Texas Health Science Center at San Antonio, San Antonio, Texas

Conflicts of interest: authors report none.

\section{CORRESPONDING AUTHOR}

A/Prof Joachim Sturmberg

PO Box 3010

Wamberal, NSW 2260

Australia

jp.sturmberg@gmail.com

\begin{abstract}
PURPOSE Over the past 7 decades, theories in the systems and complexity sciences have had a major influence on academic thinking and research. We assessed the impact of complexity science on general practice/family medicine.

METHODS We performed a historical integrative review using the following systematic search strategy: medical subject heading [humans] combined in turn with the terms complex adaptive systems, nonlinear dynamics, systems biology, and systems theory, limited to general practice/family medicine and published before December 2010. A total of 16,242 articles were retrieved, of which 49 were published in general practice/family medicine journals. Hand searches and snowballing retrieved another 35. After a full-text review, we included 56 articles dealing specifically with systems sciences and general/family practice.
\end{abstract}

RESULTS General practice/family medicine engaged with the emerging systems and complexity theories in 4 stages. Before 1995, articles tended to explore common phenomenologic general practice/family medicine experiences.

Between 1995 and 2000, articles described the complex adaptive nature of this discipline. Those published between 2000 and 2005 focused on describing the system dynamics of medical practice. After 2005, articles increasingly applied the breadth of complex science theories to health care, health care reform, and the future of medicine.

CONCLUSIONS This historical review describes the development of general practice/family medicine in relation to complex adaptive systems theories, and shows how systems sciences more accurately reflect the discipline's philosophy and identity. Analysis suggests that general practice/family medicine first embraced systems theories through conscious reorganization of its boundaries and scope, before applying empirical tools. Future research should concentrate on applying nonlinear dynamics and empirical modeling to patient care, and to organizing and developing local practices, engaging in community development, and influencing health care reform.

Ann Fam Med 2014;66-74. doi:10.1370/afm.1593.

\section{INTRODUCTION}

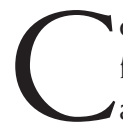

omplex adaptive systems are defined as collections of many different components (agents) interacting in nonlinear ways in the absence of any external supervisory influence. The behaviors of a complex adaptive system cannot be explained by the behavior of specific agents (reductionism)i instead, complex adaptive systems show emergent behaviors. Table 1 provides definitions for core terms from systems sciences and their characteristic effects on system behaviors. ${ }^{1}$

Complex systems theories emerged during the second half of the 19th century as physicists, mathematicians, chemists, and others searched for better explanatory models to describe and predict the behavior of phenomena under study. The reductionist model, dominant since the 17 th century, had led to important discoveries of human physiology and pathophysiology, laying the foundation for an extraordinary rise in diagnostic and therapeutic effectiveness. These developments, coupled with sophis- 
ticated technologies during the 20th century, led to fragmentation of medicine according to organ systems, procedural interventions, or both. One of the benefits of complexity science, as a new mode of scientific thinking, is its ability to overcome this fragmentation and the limitations it imposes on our understanding of the etiology, diagnosis, and treatment of illness.

Important until the second half of the 19th century, general practice and family medicine (hereafter general/family practice) became increasingly marginalized during the early decades of the 20th century. Only after World War II did this discipline reestablish itself as an independent one, starting with the formation of the American Academy of General Practice, now American Academy of Family Physicians (AAFP), in 1947; the Royal College of General Practitioners (RCGP) in 1952; and, finally, the World Organization of National Colleges and Associations (WONCA) of general/family practice in 1972 .

The postwar period also saw the rapid development of systems and complexity theory and its application in different disciplines, medicine being one notable exception. Figure 1 provides a timeline highlighting the parallel developments of the discipline and systems sciences, and the long delay and stepwise adoption of the new science by general/family practice.

We performed a search of the general/family practice literature from the 1970 s to the present, and provide an integrative historical narrative review ${ }^{2}$ of the coevolution of general/family practice and systems sciences.

\section{METHODS}

We searched MEDLINE for all articles pertaining to systems and complexity sciences using the following systematic strategy: medical subject heading [humans] combined with the terms complex adaptive systems, nonlinear dynamics, systems biology, and systems theory. The search was limited to the English and German languages and articles published before December 2010.

We retrieved 16,242 articles, 49 of which were published in general/family practice journals. Manual and citation searches retrieved another 35 articles published in these journals. A full-text review of all articles yielded 56 articles that fulfilled the inclusion criteria: a focus on systems and complexity sciences in general/family practice (Figure 2; for more details see Figures $1 \mathrm{~S}$ and $2 \mathrm{~S}$ and Table $1 \mathrm{~S}$ at dx.doi.org/10.5061/dryad.kf251).

We sorted the articles by publication date and evaluated them according to the guidelines in Integrative Review of Research. ${ }^{2}$ One author (J.P.S.) extracted an initial list of core themes. All authors then independently proposed additional themes. We used the immersion/ crystallization approach, ${ }^{3}$ looking for patterns and connections, to identify the stages of engagement with systems and complexity in general/family practice research and practice.

\section{RESULTS}

Comparative thematic analysis of the articles suggests that general/family practice literature became engaged

Table 1. Properties of Complex Adaptive Systems

\begin{tabular}{|c|c|c|}
\hline Property & Description & Notes \\
\hline Nonlinearity & $\begin{array}{l}\text { In nonlinear equations, the outputs are not } \\
\text { proportional to their inputs. }\end{array}$ & $\begin{array}{l}\text { Nonlinearity (1) can lead to sudden massive changes of the system and } \\
(2) \text { is sensitive to initial conditions. }\end{array}$ \\
\hline Attractor & $\begin{array}{l}\text { An attractor is a point toward which a vari- } \\
\text { able, moving according to the dictates of a } \\
\text { dynamic system, evolves over time. }\end{array}$ & $\begin{array}{l}\text { Points that get close enough to the attractor remain close even if slightly } \\
\text { disturbed. }\end{array}$ \\
\hline $\begin{array}{l}\text { Open to } \\
\text { environment }\end{array}$ & $\begin{array}{l}\text { Living systems continuously interact with their } \\
\text { environment, for example, exchanging mate- } \\
\text { rial, energy, people, capital, and information. }\end{array}$ & $\begin{array}{l}\text { In open systems, nonlinear responses to the external environment can lead } \\
\text { to sudden massive and stochastic changes. }\end{array}$ \\
\hline $\begin{array}{l}\text { Self- } \\
\text { organization }\end{array}$ & $\begin{array}{l}\text { Self-organization is a process whereby some } \\
\text { form of global order or coordination arises } \\
\text { out of the local interactions between the } \\
\text { components of an initially disordered system. }\end{array}$ & $\begin{array}{l}\text { Self-organization relies on } 4 \text { basic principles: recursive feedback (positive } \\
\text { and negative), a balance of exploitation and exploration, and multiple } \\
\text { interactions. }\end{array}$ \\
\hline Emergence & $\begin{array}{l}\text { Emergence is the way in which complex sys- } \\
\text { tems and patterns arise out of a multiplicity } \\
\text { of relatively simple interactions. }\end{array}$ & $\begin{array}{l}\text { Emergence (1) arises from intricate causal relations across different scales and } \\
\text { feedback (interconnectivity) and ( } 2 \text { ) the emergent behavior or properties are } \\
\text { not a property of any single such entity, nor can they easily be predicted or } \\
\text { deduced from behavior in the lower-level entities, that is, they are irreducible. }\end{array}$ \\
\hline $\begin{array}{l}\text { Pattern of } \\
\text { interaction }\end{array}$ & $\begin{array}{l}\text { All parts in a system involve predictable, } \\
\text { repetitive processes. }\end{array}$ & $\begin{array}{l}\text { Pattern of interaction can result from (1) different combinations of agents } \\
\text { leading to the same outcome, or (2) the same combination of agents lead- } \\
\text { ing to different outcomes. }\end{array}$ \\
\hline $\begin{array}{l}\text { Adaptation and } \\
\text { evolution }\end{array}$ & $\begin{array}{l}\text { Adaptation is the process of change due to } \\
\text { changes in the environment. }\end{array}$ & $\begin{array}{l}\text { Evolution is the persistence of a change into the future. Adaptation and evolu- } \\
\text { tion (1) occur in numerous diseases over many years, during which time the } \\
\text { whole body system adapts to function in the altered environment; ( } 2 \text { ) change } \\
\text { the whole system and are not restricted to a few clinically measurable fac- } \\
\text { tors; and (3) lead to a new homeostasis with new dynamic interactions. }\end{array}$ \\
\hline Coevolution & $\begin{array}{l}\text { Coevolution is the change of an object trig- } \\
\text { gered by the change of a related object. }\end{array}$ & $\begin{array}{l}\text { Coevolution results in parallel development of a subsystem with new charac- } \\
\text { teristics and dynamics. }\end{array}$ \\
\hline
\end{tabular}




\section{Figure 1. Timelines of the emergence of systems and complexity sciences, the discipline of general practice/family medicine, and the stepwise adoption of systems and complexity sciences into general practice/family medicine research and literature.}

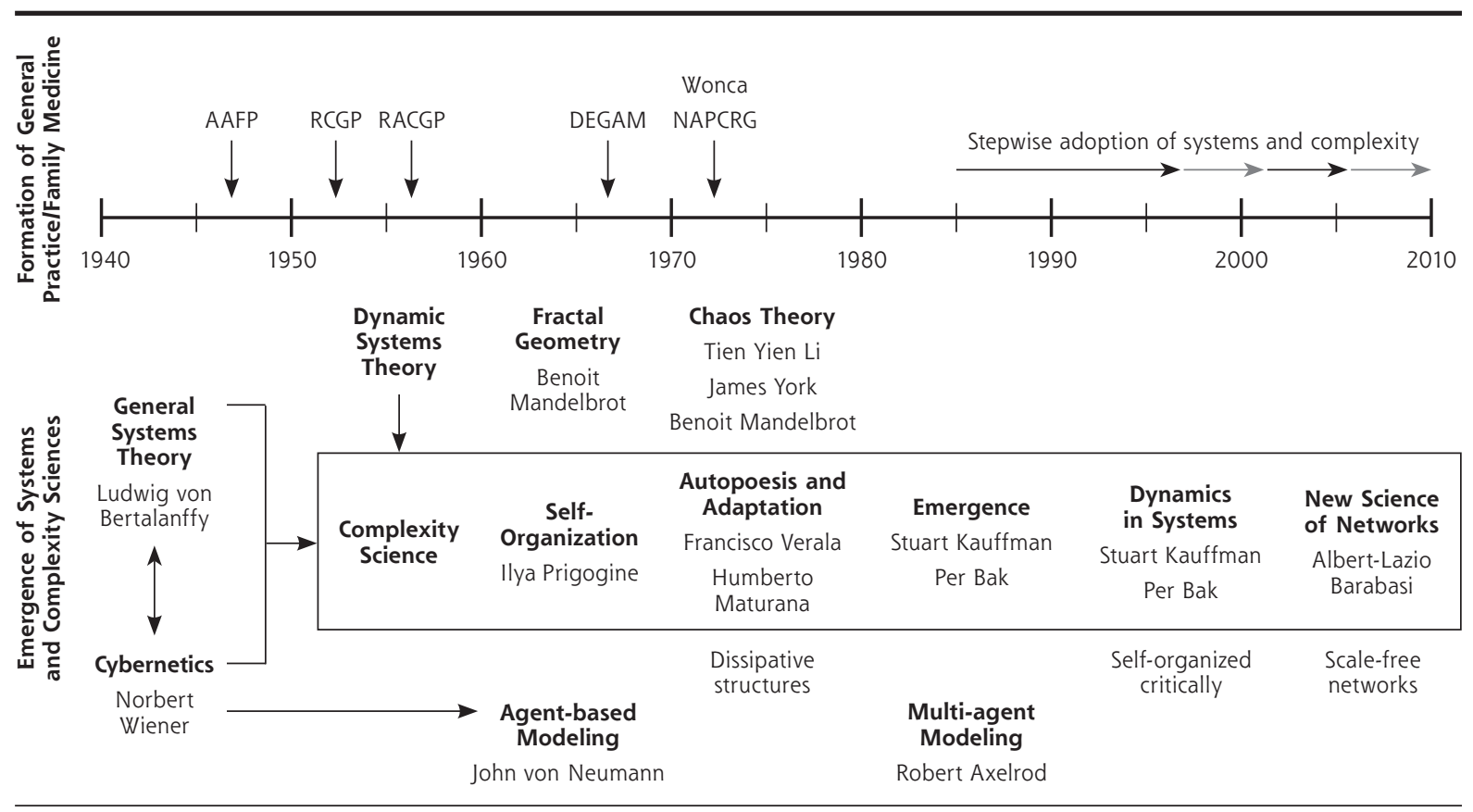

GP = general practice; FM = family medicine; AAFP = American Academy of Family Physicians; DEGAM = German Society of General Practice and Family Medicine; NAPCRG $=$ North American Primary Research Group; RACGP $=$ The Royal Australian College of General Practitioners; RCGP = Royal College of General Practitioners; WONCA $=$ World Organization of National Colleges and Associations.

with systems and complexity theories in 4 stages. Before 1995, articles explored common phenomenologic general/family practice experiences. ${ }^{4-13}$ In the period between 1995 and 2000, articles instead began to describe the complex adaptive nature of general/ family practice, ${ }^{14-22}$ while those published between 2000 and 2005 concentrated on the system dynamics of medical practice. ${ }^{23-29}$ After 2005, articles increasingly applied the breadth of complexity science theories to health care, health care reform, and the future of medicine (Table 2). ${ }^{30-58}$

\section{Before 1995}

In the years before 1995, phenomenologic experiences opened links to systems and complexity sciences. In the 1970s, general/family practice engaged in systems and complexity conversations, which led to a reexamination of clinical observations and experiences (refer to Table $2 \mathrm{~S}$ at dx.doi.org/10.5061/dryad.kf251) and a recognition that systems and complexity theory could offer a more effective, context-based understanding of illness in individuals, families, and the community. During this period, the notion emerged that patients should be understood as belonging to interconnected, overlapping systems (open to environment) that interact and influence one another in nonlinear ways (adap- tation, evolution, coevolution), with agents interacting through multicausal feedback loops (pattern of interaction, emergence, nonlinearity).

Family therapists were the first to realize that family as well as therapeutic relationships occur in a systems environment ${ }^{4}$ and could best be described through a cybernetic model. ${ }^{9}$ They noticed that interactions between variables hold the key to understanding observed patterns of health and illness. ${ }^{6,9}$ To adequately understand a patient's illness, practitioners must account for the effect of variables from overlapping systems such as family, suburb, or work. ${ }^{6,9}$ Hence, clinical reasoning must follow nonlinear, feedbackdriven, dynamics-reflected as the well-known circular process of "diagnosis as treatment" and "treatment as diagnosis."

Using this new approach, systems and complexity thinking challenged the prevailing scientific paradigm of disease causation, diagnostic reasoning, and therapeutic intervention for the first time. McWhinney ${ }^{7,10}$ in particular recognized paradigmatic inconsistencies in the biomedical model and emphasized the need to move beyond reductionist scientific generalities of diseases to holistic understandings of particular individuals in their biosocial contexts. Recognizing that each patient's presentation in the consultation is one par- 


\section{Figure 2. Search strategy.}

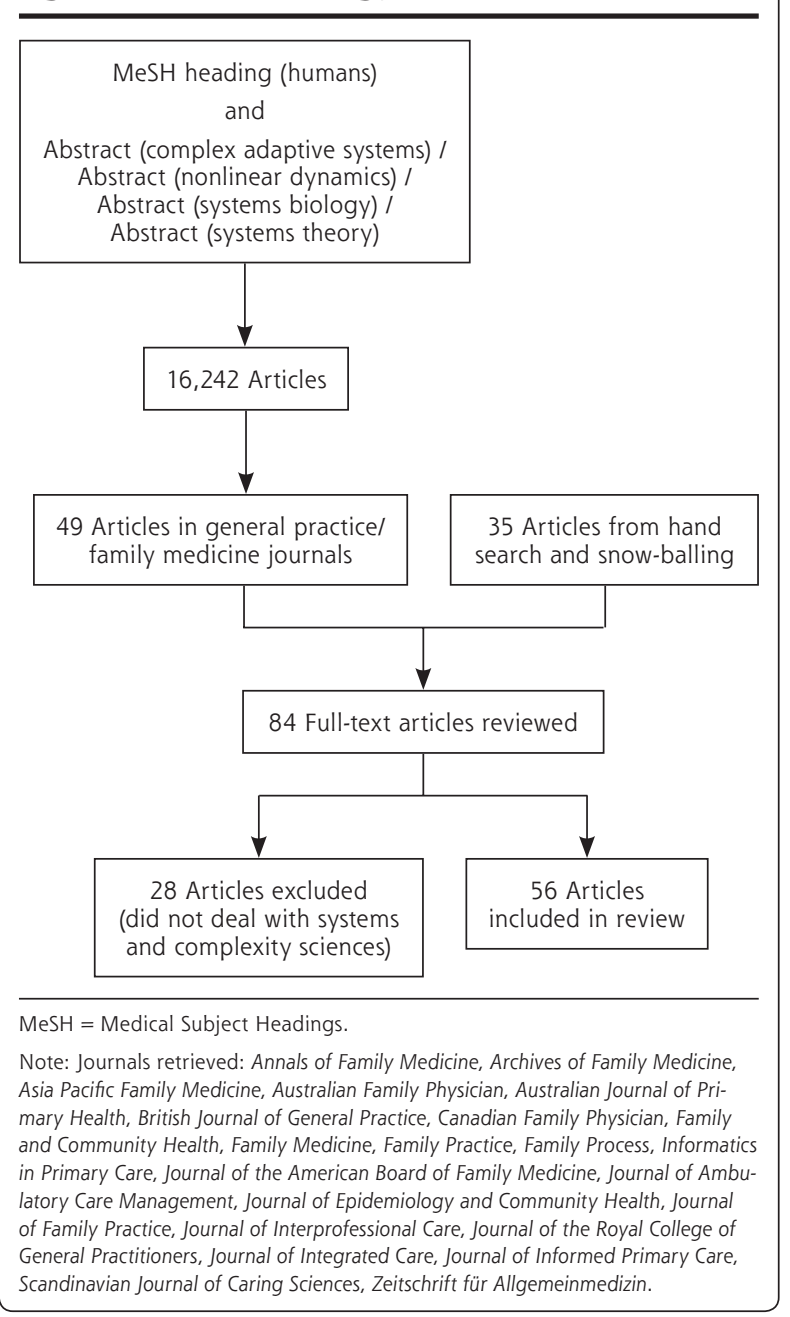

ticular instance of their health journey acknowledges that both illness and healing are dynamic adaptive states. McWhinney's insights led to his proposal for shifting medical thinking towards a Geisteswissenschaft (humanities) of medicine that links the social with the natural sciences.

Furthermore, culture provides the framework for creating meaning out of the experience of health, and of feeling and being ill. ${ }^{11}$ Illness and healing reside in a person's complex interacting set of values, expectations, and images of oneself and others, and healing becomes a meaning/sense-making process in an individual context. Thus, context, long seen as the enemy of "natural" scientific research, became a rich field of study and knowledge generation. ${ }^{11}$

These early investigations followed in Husserl's phenomenologic tradition ${ }^{59}$ and focused on both the philosophy and empiric science of health and disease, and on medical interventions and the role of the physician in health care and society.

\section{5-2000}

The years 1995-2000 entailed a focus on the complex adaptive nature of general/family practice. Academic activity in general/family practice during this period exhibited a high degree of confidence in the capacity of systems and complexity science to advance our understanding of the nature of medical care (Table $3 S$ at dx.doi.org/10.5061/dryad.kf251), especially the variability in patients' illness presentation, behavior, and recuperation (nonlinear dynamics, emergence). A second line of activity applied systems and complexity thinking to the organization and function of health care systems, and highlighted the influence of attractors on the operation of, and learning in, health system organizations and their provision of clinical care (pattern of interaction, self-organization, adaptation, coevolution).

Family physicians increasingly looked to chaos theory to help guide their provision of care for individuals, treating their patients as multivariable, nonlinear, nonperiodic systems. ${ }^{14} \mathrm{McW}$ hinney's work ${ }^{15}$ was again pivotal. He outlined the characteristics of general/family practice in systems and complexity terms, emphasizing the following: (1) the discipline is defined by the relationship between physician and patient $t_{i}(2)$ practitioners think $^{2}$ about the nexus between the person and his/her illness; (3) practitioners embrace the unique multilevel and nonlinear properties of living systems - growth, regeneration, healing, learning, self-organization, and selftranscendence (what McWhinney termed the organismic metaphor); and (4) as a discipline, general/family practice transcends the dualistic separation of body and mind.

For McWhinney, systems thinking has 3 implications $^{15}$ : first, the etiology of illness and disease is understood in terms of causal network relationships rather than as a linear process; second, dichotomous (either/ or) questions are meaningless; and third, through their properties of self-organization, learning, and transcendence, organisms behave in a mindful way, that is, each agent within a system has the capacity to act both independently and interconnectedly. Hence, disease labels may be less important than the context in which disease occurs. ${ }^{16}$ Understanding these interconnections explains the occurrence of illness without identifiable pathology_often termed somatization-and moves beyond the reductionism of mind-body dualism.

By looking at interconnections to better understand the function of general/family practices, researchers demonstrated the importance of attractors. It became clear that the agents in a practice are not truly independent, and that interactions among key agents provide a more powerful explanation for the behavior of a practice than individual knowledge and behaviors. Furthermore, change was more likely to occur where that change enhanced existing attractors or created new ones, or 
when practices became aware of their attractors and internal operational models. Lack of attention to these issues explains why guidelines, continuing medical education, and standardized interventions often failed. Rationality and knowledge do not matter to complex adaptive systems such as general/family practices unless they fit the practice system's patterns and attractors. ${ }^{18,20}$

The ongoing preference of patients and physicians for a personal relationship and for patient-centered care was recognized as the core attractor of general/family practice. Indeed, general/family practice emerged as the crucial discipline within the health care system that integrates the health care needs of patients across the life trajectory and in diverse care locations. Where general/ family practice was unable to fulfill this role adequately, it was difficult to achieve high-quality patient care. ${ }^{21}$

\section{0-2005}

The first 5 years of the new century saw a focus on the system dynamics of medical practice. During this period, researchers and academics increasingly applied systems and complexity science theories to broad general/family practice issues, including the place of this discipline in the community, professional leadership, and the therapeutic relationship (Table $4 \mathrm{~S}$ at dx.doi. org/10.5061/dryad.kf251).

It is now recognized that general/family practice's role in the health care system is to deliver care that meets the needs of both local communities and individuals. To achieve this goal, individual practices must be uniquely adapted to local conditions (ie, meet local expectations and community values), and understand their local competition and environment. To achieve

Table 2. Stepwise Adoption of Systems and Complexity Sciences Into General/Family Practice Research and Literature, by Adoption Period

\begin{tabular}{|c|c|c|}
\hline $\begin{array}{l}\text { Period and Key } \\
\text { Complexity } \\
\text { Science Theories }\end{array}$ & Critical Assessment: Study Design and Focus & What These Articles Added to Our Understanding \\
\hline $\begin{array}{l}\text { Before } 1995^{4-13}: \\
\text { general systems } \\
\text { theory and } \\
\text { cybernetics }\end{array}$ & $\begin{array}{l}\text { Descriptive design }{ }^{4-7,9-13} \\
\text { The dynamic nature of the illness trajectory } \\
\text { Teaching family dynamics in residency programs, }{ }^{6} \text { using } \\
\text { genograms to understand family dynamics, }{ }^{9} \text { and illus- } \\
\text { trating chaotic system dynamics within families }{ }^{12} \\
\text { Ecosystemic description of the diagnosis }{ }^{4} \\
\text { The need for a paradigm shift } \\
\text { Medicine as a human science deals with the nonlinear } \\
\text { causality of illness and acknowledges the patient as a } \\
\text { self-organizing system }{ }^{10} \\
\text { Culture as a meaning system influences health and ill- } \\
\text { ness, their meaning, and the response to treatment }{ }^{11} \\
\text { The need to integrate care for patients with cancer }{ }^{13} \\
\text { Research design } \\
\text { Survey: first attempt to characterize work patterns of } \\
\text { different specialties for specific conditions }\end{array}$ & $\begin{array}{l}\text { Exploration of the philosophy of health and disease } \\
\text { and the role of the physician in society } \\
\text { Holism as a key concept of general/family practice } \\
\text { Context matters } \\
\text { - The role of the family, } n \rightarrow 1,1 \rightarrow n \text {, and } n \rightarrow n \text { relationships } \\
\text { - Nonlinear dynamics determine the individual patient's } \\
\text { understanding and response to his illness } \\
\text { - Culture explains illness experience and therapeutic } \\
\text { responses } \\
\text { Ecological dynamics of disease and disease management } \\
\text { Nonlinear dynamics of healing } \\
\text { The outcome of treatments affecting dynamic systems can- } \\
\text { not be precisely predicted }\end{array}$ \\
\hline $\begin{array}{l}\text { 1995-200014-22: } \\
\text { initial condition, } \\
\text { self-organization, } \\
\text { and emergence }\end{array}$ & $\begin{array}{l}\text { Descriptive design }{ }^{14-16,19,22} \\
\text { The need to teach chaos theory } \\
\text { General practice defines itself by reflective multicausal } \\
\text { relationship thinking and acting } \\
\text { General practice deals with health and disease as multi- } \\
\text { factorial and interconnected personal states }{ }^{16} \\
\text { Understanding general practice through chaos and } \\
\text { complexity theories }^{19} \\
\text { Research design }{ }^{17-21} \\
\text { Case study: response to diabetes care intervention }{ }^{17} \\
\text { Observational study: prevention in primary care } \\
\text { practice } \\
\text { Methodology study: the use of different statistical tech- } \\
\text { niques, cluster analysis, and loglinear analysis } \\
\text { Observational study: change in primary care practices }{ }^{20} \\
\text { Observational study: integrative nature of primary care } \\
\text { consultation to meet patient need }{ }^{21}\end{array}$ & $\begin{array}{l}\text { Defining the discipline of general/family practice } \\
\text { To understand the apparent randomness of outcomes in the } \\
\text { natural world } \\
\text { Relationships matter } \\
\text { - The doctor-patient interaction, the particular circumstances } \\
\text { of the patient, the organismic behavior of the body, the } \\
\text { integration of mind and body } \\
\text { - Illness and healing result from network relationships } \\
\text { - The needs and benefits of ongoing therapeutic } \\
\text { relationships } \\
\text { - The link between the patient's illness and his community } \\
\text { - To facilitate practice change } \\
\text { Sudden changes in behaviors in relation to a change in cir- } \\
\text { cumstances (now known as cusp catastrophe) } \\
\text { - Patient self-management } \\
\text { - Consultation behaviors } \\
\text { General practices are complex adaptive systems whose stabil- } \\
\text { ity arises from adherence to their attractor } \\
\text { Change requires awareness of and change in the attractor } \\
\text { Without general/family practice, the health system becomes } \\
\text { dysfunctional }\end{array}$ \\
\hline
\end{tabular}

continued 
Table 2. Stepwise Adoption of Systems and Complexity Sciences Into General/Family Practice Research and Literature, by Adoption Period (continued)

\begin{tabular}{|c|c|c|}
\hline $\begin{array}{l}\text { Period and Key } \\
\text { Complexity } \\
\text { Science Theories }\end{array}$ & Critical Assessment: Study Design and Focus & What These Articles Added to Our Understanding \\
\hline \multirow{9}{*}{$\begin{array}{l}\text { 2000-200523-29: } \\
\text { dynamics in } \\
\text { systems }\end{array}$} & Descriptive design ${ }^{23-29}$ & The function of medical practice \\
\hline & \multirow{2}{*}{$\begin{array}{l}\text { Applying complexity science principles to the function } \\
\text { of medical practice } \mathrm{e}^{23} \text { and the understanding of the } \\
\text { biopsychosocial mode }{ }^{28}\end{array}$} & Interdependence of its members \\
\hline & & $\begin{array}{l}\text { Emergent function arises from its historical context (initial } \\
\text { condition) }\end{array}$ \\
\hline & $\begin{array}{l}\text { Family practices are local professional complex adap- } \\
\text { tive systems }{ }^{24}\end{array}$ & Variability characterizes clinical practice \\
\hline & \multirow{2}{*}{$\begin{array}{l}\text { Understanding and managing in complex adaptive } \\
\text { systems }^{26}\end{array}$} & Small change can result in large outcomes and vice versa \\
\hline & & Transformational leadership acknowledges the networked \\
\hline & $\begin{array}{l}\text { Constructing a complexity model of continuity of care } \\
\text { and illustrating its veracity using previously published } \\
\text { outcomes data } 27\end{array}$ & $\begin{array}{l}\text { structure of the system and there interdependent interactions } \\
\text { Leaders maintain creative tension between cooperation and } \\
\text { competition }\end{array}$ \\
\hline & \multirow[t]{2}{*}{$\begin{array}{l}\text { Understanding the interconnected issues affecting the } \\
\text { primary care workforce } \text { crisis }^{29}\end{array}$} & $\begin{array}{l}\text { Feedback loops show the patterns of interactions and out- } \\
\text { comes in a complex adaptive system }\end{array}$ \\
\hline & & $\begin{array}{l}\text { Systems diagrams as a tool to seeing and appreciating inter- } \\
\text { connectedness and feedback }\end{array}$ \\
\hline \multirow{19}{*}{$\begin{array}{l}\text { After 200530-58: } \\
\text { networks }\end{array}$} & Descriptive design ${ }^{30-32,35-41,43-47,49-54,57,58}$ & \multirow{2}{*}{$\begin{array}{l}\text { The application of systems theories to general/family } \\
\text { practice activities }\end{array}$} \\
\hline & Healing is the process of reestablishing wholeness ${ }^{30,45,47,49}$ & \\
\hline & \multirow{2}{*}{$\begin{array}{l}\text { Consultation dynamics }{ }^{31,45,46} \text { and outcomes } \\
\text { Care team development, practice development, and } \\
\text { dynamics } 35,57,58\end{array}$} & $\begin{array}{l}\text { Interdependence and coevolution of patient and doctor } \\
\text { in the healing relationship }\end{array}$ \\
\hline & & $\begin{array}{l}\text { Attractors limit the possible range of behaviors and resist } \\
\text { or limit change in patient outcomes }\end{array}$ \\
\hline & \multirow{2}{*}{$\begin{array}{l}\text { Health systems and health system reform } 36-38,43,44,50,52-54 \\
\text { Toward an integrated understanding of health } \\
\text { disease }{ }^{41,47,43,45,47,49} \text { and }\end{array}$} & $\begin{array}{l}\text { Physiologic variability is a sign of health, loss of variability } \\
\text { a sign of disease }\end{array}$ \\
\hline & & Health and illness are personal dynamic states, influenced \\
\hline & \multirow{2}{*}{$\begin{array}{l}\text { Developing a safe health care environment }{ }^{39} \\
\text { Complexities of understanding and managing }\end{array}$} & by context and variable over time, and the emergence of \\
\hline & & \\
\hline & \multirow{2}{*}{$\begin{array}{l}\text { comorbidity }{ }^{40,43-45} \\
\text { The generalist's way of knowing }\end{array}$} & \multirow{2}{*}{$\begin{array}{l}\text { Patient consultation rates in general and for specific condi- } \\
\text { tions follow power law distributions }\end{array}$} \\
\hline & & \\
\hline & Primary care paradox ${ }^{52}$ & Dynamic adaptive processes facilitate team care development \\
\hline & Research design $33,34,42,48,55,56$ & Understanding the structure and function of health systems \\
\hline & \multirow{2}{*}{$\begin{array}{l}\text { Database analyses } \\
\text { - Patient consultation rates for general and specific } \\
\text { conditions } \\
\text { - Determining the complexity of primary care } \\
\text { consultations }{ }^{56}\end{array}$} & $\begin{array}{l}\text { as complex adaptive systems } \\
\text { Generalists understand that their knowledge base is cross- } \\
\text { disciplinary, context sensitive, and emergent over time }\end{array}$ \\
\hline & & $\begin{array}{l}\text { Holism results in better quality, better health, greater equity, } \\
\text { and lower cost for individuals and populations }\end{array}$ \\
\hline & \multirow{5}{*}{$\begin{array}{l}\text { Multimethod studies } \\
\text { - Reflective process to inform improvement in primary } \\
\text { care practice } \\
\text { - Clinical governance: toward a collaborative partner- } \\
\text { ship approach } \\
\text { Systematic review: dynamics of care planning } \\
\text { Cross-sectional survey: uncertainty in primary care }\end{array}$} & $\begin{array}{l}\text { Safety in health care is an emergent process within the } \\
\text { dynamics of the health systems as a learning organization }\end{array}$ \\
\hline & & $\begin{array}{l}\text { System tools such as concepts maps and system diagrams } \\
\text { facilitate an understanding of the patient's illness and pro- } \\
\text { vide leverage points for care interventions }\end{array}$ \\
\hline & & \multirow{2}{*}{$\begin{array}{l}\text { System dynamic approaches reduce the risk of making } \\
\text { unforeseen mistakes }\end{array}$} \\
\hline & & \\
\hline & & $\begin{array}{l}\text { A holistic epistemology is associated with less stress reaction } \\
\text { to uncertainty among primary care physicians }\end{array}$ \\
\hline
\end{tabular}

such adaptation, each practice must develop unique local structures and functions. Its ability to do so, however, is constrained by external influences, such as the capacities of the health care system, financial limitations, regulation, and culture. ${ }^{24}$

To better understand such adaptation, organization-focused research demonstrated that practice function arises from the nonlinear relationships and interactions among the practice's agents (physicians, nurses, administrative staff). Observations also highlighted that well-functioning practices had transformational leaders able to use complexity insights to transform their organization, recognizing the interplay between its structure and self-organizing networks. ${ }^{26}$ At the same time, clinical quality improvement strategies that adopted ideas from complexity science proved more successful than traditional linear approaches. ${ }^{24}$

Likewise, exploration of the biopsychosocial model of care and the consultation showed that they are better understood as emergent, dependent on the individuals involved and the conditions at the time of presentation. Given this fact, models of care need to account for circular causalities, whereby feedback loops, either self-balancing (stabilizing) or self-rein- 
forcing (amplifying), maintain observable patterns over time and have an impact on outcomes of care. ${ }^{26,27}$

Systems and complexity tools thus provide the means to understand the patterns of patients' illness dynamics and adaptive responses. Interrupting unhelpful dynamic patterns and facilitating the emergence of new ones will assist the healing process. Replacing objective detachment with reflective participation would result in greater warmth and caring in the therapeutic encounter. ${ }^{28}$ Such deeper models will need to be complemented with approximations that describe the dynamics as a practical guide to clinical practice, however, always being aware that such approximations may have noticeable unintended consequences. ${ }^{28}$ The overall dynamics of the therapeutic relationship appear to be reflected in the dynamics and the level of continuity of care, which in turn affect health outcomes. ${ }^{27}$

\section{After 2005}

This last period involved application of complex system theories to health care, health care reform, and the future of medicine. It saw a transition from the largely theoretical engagement with complexity science to its pragmatic application-dealing with illness and disease, providing more effective consultations, leading change in practice organization, understanding primary care as an interconnected multidimensional system, and influencing health care reform (Table $5 \mathrm{~S}$ at http://dx.doi.org/10.5061/dryad.kf251). We discuss these aspects in more detail below.

\section{Dealing With Illness/Disease While Providing More Effective Consultations}

The physiology of health and disease shows typical nonlinear dynamics; physiologic variability is a sign of health, and loss of variability is a sign of disease. Subtle changes in these patterns, like a minor illness in a previously stable patient with chronic disease, can dramatically change the patient's illness trajectory, acting as a tipping point. Nevertheless, attractors limit the range of possible behaviors, resulting in well-recognized patterns and trajectories of specific illnesses. Paradoxically, the more unstable, that is, further from equilibrium and closer to irreversible an internal system failure is, the more predictable its patterns of decline and therapeutic responses. Restoring health means optimizing patients' nonlinear physiologic dynamics to better adapt to internal and external challenges. ${ }^{32}$

In a similar way, complexity theory provides tools to understand and deal with uncertainty and nonlinearity in the consultation. ${ }^{31}$ Using system diagrams resulted in a deeper understanding of the many contextual agents and their influence on the patient's illness, ${ }^{45,46}$ and especially benefited patients with chronic pain experiences. ${ }^{41}$
Individual illness experiences and care-seeking behaviors follow power law relationships in general (eg, average consultation rates in UK practices), and for specific conditions (eg, back pain), suggesting that the complex relationships between patient and physician themselves strongly influence consultation rates. ${ }^{33}$

Finally, the general/family practice encounter shows a higher degree of complexity per hour when compared with specialist encounters. This higher complexity and associated uncertainty is not only important to patient care, but may account for higher physician stress. ${ }^{56}$

\section{Leading Change in Practice Organizations}

Complex adaptive systems thinking has pragmatic consequences for transforming general/family practice. First, systems usually return close to their previous state in response to disturbance. Looking at reform, the magnitude of change has little relationship to the size of the intervention, and unintended consequences occur frequently. Second, knowledge negotiated among members of a community of practice is more likely to be applied in response to challenges. Last, the education sector itself has come to recognize that adult education is best guided by concepts of continued self-organized learning. ${ }^{36} \mathrm{Com}$ plex adaptive systems approaches are consequently more likely to achieve lasting quality improvement ${ }^{55}$ and avoidance of "surprising unintended consequences." ${ }^{139}$

\section{Understanding Primary Care as an Interconnected Multidimensional System}

Since 2005, several authors have explored the multilevel, multidimensional nature of primary care. ${ }^{49-53}$ Core to generalist practice are the view of the whole patient, the ability to deal with the uncertainties of people's illnesses, and the changing context-dependent dynamics of illness over time. Good outcomes for a population are strongly linked to the level of primary care implementation, with its focus on individually appropriate and accessible care. Primary care functions in adaptive cycles of growth, accumulation, restructuring, and renewal within an ever-changing health system.

\section{Influencing Health Care Reform Efforts}

The health care vortex metaphor was proposed to demonstrate how personal health experiences could drive health care, health service delivery, and health care policy in an integrated fashion. The model highlights that achieving an integrated patient-centered health care system requires leaders able to simultaneously connect individual patient care, practice organization, and community needs with the system's organizational and accountability demands, as well as policy makers able to allow the emergence of local solutions to common problems. ${ }^{37,38}$ 


\section{DISCUSSION}

This historical narrative review describes the development of general/family practice in relation to complex adaptive systems theories. Although both disciplines emerged in parallel, it took general/family practice 30 to 40 years to start engaging with systems and complexity sciences as a means to better understand the nature of health and illness in general and its implications for primary care in particular.

Complex systems theories provided an initial framework for a generalist understanding of health, illness, and disease as interconnected and context-dependent states of human experience. Viewed from this perspective, the task of the clinical consultation broadens from simple identification of a specific condition toward an untangling of the circumstances and the patient's understandings of particular illness episodes, before exploring how to best improve or maintain health.

The past 15 years have seen an expansion of systems and complexity thinking in primary care, exploring practice organization and organizational learning, the nature of health, illness, and disease $e_{i}$ the nature of clinical practice; and the behavior of illnesses in particular patients and patient groups. There is an increasing awareness of the importance of network relationships, initial conditions, self-organization, and emergence as the background to understanding a patient's problem or a practice's performance. Recognizing the complex adaptive nature of health, illness, and care has broadened our understanding of patients' health care needs, and made it possible to describe system constraints ${ }^{60}$ and unintended consequences of system interventions ${ }^{61}$ on meeting those needs.

General/family practice researchers and academics have both explicitly and implicitly framed the emerging discipline in systems and complexity sciences terms. There has been a scholarly recognition of the importance of dynamics, context, agency, attractors, and interdependences in patient care, education, and health care organization. These insights have influenced the philosophical discourses of the discipline, contributing to the growth of its unique identity and its relationships with the broader health care system.

Systems and complexity thinking was embraced as a transformational tool to link the specific with the particular of whole-person care-the patient as a subsystem of larger systems such as family, community, society, and the health care system. Not surprisingly, this approach resonates well with general and family practitioners as it much more accurately describes the high degree of variability they encounter among patients presenting with the same condition.

Systems and complexity sciences provide valuable research frameworks that allow researchers to make sense of the dynamic phenomena observed in primary care. Recent empirical research has provided findings that indicate the value of understanding the behaviors of many common conditions as complex phenomena, for example, psychiatric illness, intimate partner violence, cardiac and respiratory diseases, aging, and avoidable hospitalization. ${ }^{62}$

Metaphors remain important, powerful, and valid means for understanding complex phenomena in and generating new knowledge for primary care. The challenge for the future, alluded to by critical voices, is to progress from well-established conceptual and philosophical models to the pragmatic application of nonlinear dynamics and modeling. Access to "big data" is required for dynamic systems modeling, especially of linked subsystems, as each has its own dynamics but is also affected by cross-system dynamics. This work can be applied to patient care, practice organization, and community development, and to influencing health care reform. Such empirical work needs to be published more consistently in general/family practice journals.

To read or post commentaries in response to this article, see it online at www.annfammed.org/content/12/1/66.

Key words: complex adaptive systems; nonlinear dynamics; systems biology; systems theory; general practice; family medicine; philosophy of medicine; philosophy of general practice; historical review; integrative review

Submitted March 31, 2012; submitted, revised, April 20, 2013; accepted May 22, 2013.

Acknowledgment: We thank Craig Ronalds for his valuable assistance with the preparation of the manuscript.

\section{References}

1. Cilliers P. Complexity and Postmodernism. Understanding Complex Systems. London, England: Routledge, 1998.

2. Smith J. Reviews: From Systematic to Narrative LHL Guides at UAB Lister Hill Library of the Health Sciences. Birmingham, Alabama: Lister Hill Library, 2012. http://libguides.Ihl.uab.edu/. Accessed Dec 6, 2013.

3. Crabtree BF, Miller WL, eds. Doing Qualitative Research. Thousand Oaks, CA: Sage Publication, 1999.

4. Keeney BP, Sprenkle DH. Ecosystemic epistemology: critical implications for the aesthetics and pragmatics of family therapy. Fam Process. 1982;21(1):1-19.

5. Freer CB. Description of illness: limitations and approaches. J Fam Pract. 1980;10(5):867-870.

6. Christie-Seely J. Teaching the family system concept in family medicine. J Fam Pract. 1981;13(3):391-401.

7. McWhinney IR. Changing models: the impact of Kuhn's theory on medicine. Fam Pract. 1984;1(1):3-8.

8. Mendenhall RCMS, Moynihan CJP, Radecki SEP. The relative complexity of primary care provided by medical specialists. Med Care. 1984;22(11):987-1001.

9. Like RC, Rogers J, McGoldrick M. Reading and interpreting genograms: a systematic approach. J Fam Pract. 1988;26(4):407-412.

10. McWhinney IR. 'An acquaintance with particulars...' Fam Med. 1989; 21(4):296-298. 
11. Burkett GL. Culture, illness, and the biopsychosocial model. Fam Med. 1991;23(4):287-291.

12. Smith BW. Chaotic family dynamics. Arch Fam Med. 1994;3(3):231-238.

13. McWhinney IR. Caring for patients with cancer. Family physicians' role. [Editorial]. Can Fam Physician. 1994;40:16-19.

14. Markham FW. The need to teach chaos theory. Fam Med. 1995;27 (7):420-421.

15. McWhinney IR. William Pickles Lecture 1996. The Importance of Being Different. Br J Gen Pract. 1996;46(7):433-436.

16. Fabb WE, Chao DV, Chan CS. The trouble with family medicine. Fam Pract. 1997;14(1):5-11.

17. O'Connor PJ, Crabtree BF, Yanoshik MK. Differences between diabetic patients who do and do not respond to a diabetes care intervention: a qualitative analysis. Fam Med. 1997;29(6):424-428.

18. Crabtree BF, Miller WL, Aita VA, Flocke SA, Stange KC. Primary care practice organization and preventive services delivery: a qualitative analysis. J Fam Pract. 1998;46(5):403-409.

19. Griffiths F, Byrne D. General practice and the new science emerging from the theories of 'chaos' and complexity. Br J Gen Pract. 1998;48(435):1697-1699.

20. Miller WL, Crabtree BF, McDaniel R, Stange KC. Understanding change in primary care practice using complexity theory. J Fam Pract. 1998;46(5):369-376.

21. Stange KC, Jaén CR, Flocke SA, Miller WL, Crabtree BF, Zyzanski SJ. The value of a family physician. J Fam Pract. 1998;46(5):363-368.

22. Holt T. Chaos and complexity. Br J Gen Pract. 1999;49(443):483.

23. Kernick D, Sweeney K. Post-normal medicine. Fam Pract. 2001;18(4): 356-358.

24. Miller WL, McDaniel RR Jr, Crabtree BF, Stange KC. Practice jazz: understanding variation in family practices using complexity science. J Fam Pract. 2001;50(10):872-878.

25. Bro F, Kragstrup J. From black box to complex adaptive system. Scand J Prim Health Care. 2003;21(1):1.

26. Kernick D. Can complexity theory provide better understanding of integrated care? J Integrated Care. 2003;11(5):22-29.

27. Sturmberg JP. Continuity of care: a systems-based approach. Asia Pac Fam Med. 2003;2(3):136-142.

28. Borrell-Carrió F, Suchman AL, Epstein RM. The biopsychosocial model 25 years later: principles, practice, and scientific inquiry. Ann Fam Med. 2004;2(6):576-582.

29. Sturmberg J. Approaching the future of general practice-how systems thinking might help. Aust Fam Physician. 2004;33(12):1033-1035.

30. Egnew TR. The meaning of healing: transcending suffering. Ann Fam Med. 2005;3(3):255-262.

31. Innes D, Campion PD, Griffiths FE. Complex consultations and the 'edge of chaos'. Br J Gen Pract. 2005;55(510):47-52.

32. Katerndahl DA. Is your practice really that predictable? Nonlinearity principles in family medicine. J Fam Pract. 2005;54(11):970-977.

33. Love T, Burton C. General practice as a complex system: a novel analysis of consultation data. Fam Pract. 2005;22(3):347-352.

34. Stroebel CK, McDaniel RRJ Jr, Crabtree BF, Miller WL, Nutting PA, Stange KC. How complexity science can inform a reflective process for improvement in primary care practices. Jt Comm J Qual Patient Saf. 2005;31(8):438-446.

35. Batalden $P$, Ogrinc G, Batalden M. From one to many. J Interprof Care. 2006;20(5):549-551.

36. Kernick D. Wanted-new methodologies for health service research. Is complexity theory the answer? Fam Pract. 2006;23(3):385-390.

37. Sturmberg JP, Martin CM. Rethinking general practice-part 1: far from equilibrium. disease-centred and econometric-oriented health care and general practice/family medicine. Asia Pac Fam Med. 2006. http://www.apfmj-archive.com/afm5_2/afm39.pdf. Accessed Dec 26, 2013.
38. Martin CM, Sturmberg JP. Rethinking general practice-part 2: strategies for the future. patient-centred, socially and economically responsible primary care and the leadership challenges. Asia Pac Fam Med. 2006. http://www.apfmj-archive.com/afm5_2/afm48.pdf. Accessed Dec 26, 2013.

39. Sheps $S$. Reflections on safety and interprofessional care: some conceptual approaches. J Interprof Care. 2006;20(5):545-548.

40. Starfield B. Threads and yarns: weaving the tapestry of comorbidity. Ann Fam Med. 2006;4(2):101-103.

41. Brown CA. The role of paradoxical beliefs in chronic pain: a complex adaptive systems perspective. Scand J Caring Sci. 2007;21(2):207-213.

42. Elf M, Poutilova M, Ohrn K. A dynamic conceptual model of care planning. Scand J Caring Sci. 2007;21(4):530-538.

43. Griffiths F; North American Primary Care Research Group. Complexity science and its relevance for primary health care research. Ann Fam Med. 2007;5(4):377-378.

44. Martin CM. Chronic disease and illness care: adding principles of family medicine to address ongoing health system redesign. Can Fam Physician. 2007;53(12):2086-2091.

45. Sturmberg JP. Systems and complexity thinking in general practice: part 1-clinical application. Aust Fam Physician. 2007;36(3):170-173.

46. Sturmberg JP. Systems and complexity thinking in general practice. Part 2: application in primary care research. Aust Fam Physician. 2007;36(4):273-275.

47. Fugelli P. The healing dance. Why society and medicine need the general practitioner. 2008. http://folk.uio.no/pfugelli/artikler/ healing_dance.pdf. Accessed Dec 26, 2013.

48. Evans L, Trotter DR. Epistemology and uncertainty in primary care: an exploratory study. Fam Med. 2009;41(5):319-326.

49. Stange KC. A science of connectedness. Ann Fam Med. 2009;7(5): 387-395.

50. Stange KC. The problem of fragmentation and the need for integrative solutions. Ann Fam Med. 2009;7(2):100-103.

51. Stange KC. The generalist approach. Ann Fam Med. 2009;7(3):198-203.

52. Stange KC, Ferrer RL. The paradox of primary care. Ann Fam Med. 2009;7(4):293-299.

53. Stange KC, Ferrer RL, Miller WL. Making sense of health care transformation as adaptive-renewal cycles. Ann Fam Med. 2009;7(6):484-487.

54. Booth BJ, Zwar NA, Harris M. A complexity perspective on health care improvement and reform in general practice and primary health care. Aust J Prim Health. 2010;16(1):29-35.

55. Ellis B. Complexity in practice: understanding primary care as a complex adaptive system. Inform Prim Care. 2010;18(2):135-140.

56. Katerndahl DA, Wood $R$, Jaén CR. A method for estimating relative complexity of ambulatory care. Ann Fam Med. 2010;8(4):341-347.

57. Miller WL, Crabtree BF, Nutting PA, Stange KC, Jaen CR. Primary care practice development: a relationship-centered approach. Ann Fam Med. 2010;8(Suppl 1):S68-S79.

58. Taylor HA, Greene BR, Filerman GL. A conceptual model for transformational clinical leadership within primary care group practice. J Ambul Care Manage. 2010;33(2):97-107.

59. Husserl E. Experience and Judgment. Chicago, IL: Northwestern University Press, 1975.

60. Committee on Quality Health Care in America, Institute of Medicine. Crossing the Quality Chasm: A New Health System for the 21st Century. Washington, DC: National Academy Press, 2001.

61. Unintended Consequences of Health Policy Programs and Policies: Workshop Summary. Washington, DC: The National Academies Press, 2001: http://www.nap.edu/openbook.php?record_id=10192. Accessed Dec 26, 2013.

62. Sturmberg JP, Martin CM. Handbook of Systems and Complexity in Health. New York, NY: Springer, 2013. 